\title{
Corrosion Behaviour of Heat-Treated Aluminum-Magnesium Alloy in Chloride and EXCO Environments
}

\author{
S. O. Adeosun, O. I. Sekunowo, S. A. Balogun, and V. D. Obiekea \\ Department of Metallurgical \& Materials Engineering, University of Lagos, Nigeria \\ Correspondence should be addressed to S. O. Adeosun, samsonoluropo@yahoo.com
}

Received 12 September 2011; Revised 24 November 2011; Accepted 5 December 2011

Academic Editor: Rokuro Nishimura

Copyright () 2012 S. O. Adeosun et al. This is an open access article distributed under the Creative Commons Attribution License, which permits unrestricted use, distribution, and reproduction in any medium, provided the original work is properly cited.

\begin{abstract}
Machines designed to operate in marine environment are generally vulnerable to failure by corrosion. It is therefore imperative that the corrosion susceptibility of such facilities is evaluated with a view to establishing mechanism for its mitigation. In this study, the corrosion behaviour of as-cast and retrogression-reagion (RRA) specimens of aluminum alloy containing 0.4-2.0 percent magnesium additions in $\mathrm{NaCl}, \mathrm{FeCl}_{3}$, and EXCO solutions was investigated. The corrosion simulation processes involved gravimetric and electrochemical techniques. Results show substantial inducement of $\mathrm{Mg}_{2} \mathrm{Si}$ precipitates at a relatively higher magnesium addition, 1.2-2.0 percent, giving rise to increased attack. This phenomenon is predicated on the nature of the $\mathrm{Mg}_{2} \mathrm{Si}$ crystals being anodic relative to the alloy matrix which easily dissolved under attack by chemical constituents. Formation of $\mathrm{Mg}_{2} \mathrm{Si}$ intermetallic without corresponding appropriate oxides like $\mathrm{SiO}_{2}$ and $\mathrm{MgO}$, which protect the precipitates from galvanic coupling with the matrix, accentuates susceptibility to corrosion.
\end{abstract}

\section{Introduction}

Aluminum and its alloys are widely used in industry because of their light weight, high strength, and good corrosion resistance which is due to the formation of a protective oxide layer. However, under saline conditions such as those encountered in marine environments, aluminum alloys are vulnerable to localised degradation in forms of pitting and crevice corrosion. This type of corrosion involves the adsorption of an anion in particular chloride ion, $\mathrm{Cl}^{-}$, at the oxidesolution interface.

In conventional metallic materials, the strong oxidizing power of the environment is required to establish spontaneous passivity; hence, to be of practical use, metallic materials must exhibit significant level of passivity in a given environment.

The passive stable surface film acts as a barrier for the transfer of cations from the metal to the environment and for the counter diffusion of oxygen and other anions. The air-formed film must be stable without damage to the underlying alloy surface in a given environment. Chemically homogenous, single-phase amorphous alloys free from crystalline defects such as precipitates, segregates, grain boundaries, and dislocations often create conducive environment for the formation of uniform passive film without any weak points [1].

Aluminum forms a protective oxide film in the $\mathrm{pH}$ range $4.0-8.5$, but this depends on temperature, form of oxide present, and the presence of substances that form soluble complexes or insoluble salts with aluminum. This implies that the oxide film is soluble at $\mathrm{pH}$ values below 4.0 and above 8.5. However, Sziklarska and Smialowska [2] has reported the pitting potential of aluminum in chloride solutions to be relatively independent of $\mathrm{pH}$ in the range $4-9$. This was further advanced by Godard [3] to demonstrate that a deviation from neutrality, $\mathrm{PH} 7$, on both acid and alkaline sides increases the pitting rate in neutral fresh waters.

Corrosion behaviour of aluminum alloys is significantly affected by the presence of particles in the matrix [4]. Particles that contain $\mathrm{Cu}$ and $\mathrm{Mg}$ tend to be anodic relative to the alloy matrix, while those that contain $\mathrm{Fe}$ and Mn behave in cathodic manner relative to the matrix [5]. Previous works [6-8] show that $\mathrm{Mg}_{2} \mathrm{Si}$ particles tend to be anodic in relation to the matrix and can act as initiation sites for corrosion. Most often the $\mathrm{Mg}_{2} \mathrm{Si}$ phase dissolves leaving behind a cavity, which acts as a nucleation site for pitting 
TABLE 1: Al-Mg alloy chemical composition.

\begin{tabular}{lcccccccccrcr}
\hline \multirow{2}{*}{ No. of cast } & \multicolumn{1}{c}{} & \multicolumn{1}{c}{ \% Composition } & \multicolumn{4}{c}{$\begin{array}{c}\text { Si/Mg } \\
\text { ratio }\end{array}$} \\
\hline As-received & 0.296 & 0.446 & 0.073 & 0.013 & 0.016 & 0.020 & 0.34 & 0.007 & 0.009 & 98.78 & 1.312 \\
Alloy 1 & 0.269 & 0.584 & 0.024 & 0.096 & 0.021 & 0.013 & 0.42 & 0.009 & 0.004 & 98.56 & 1.390 \\
Alloy 2 & 0.276 & 0.572 & 0.023 & 0.071 & 0.018 & 0.012 & 0.91 & 0.008 & 0.005 & 98.56 & 0.629 \\
Alloy 3 & 0.219 & 0.403 & 0.021 & 0.002 & 0.003 & 0.014 & 1.23 & 0.001 & 0.007 & 98.10 & 0.328 \\
Alloy 4 & 0.253 & 0.530 & 0.088 & 0.012 & 0.017 & 0.015 & 1.52 & 0.006 & 0.005 & 97.59 & 0.349 \\
Alloy 5 & 0.414 & 0.599 & 0.025 & 0.019 & 0.015 & 0.013 & 1.81 & 0.005 & 0.004 & 97.10 & 0.331 \\
Alloy 6 & 0.319 & 0.771 & 0.024 & 0.037 & 0.019 & 0.013 & 2.02 & 0.001 & 0.006 & 96.79 & 0.382 \\
\hline
\end{tabular}

$[9,10]$. These observations were made during investigations that were carried out on commercial aluminum alloys having low Si/Mg molar ratios [11-14].

Crevice corrosion is a highly localized form of corrosion which occurs by infiltration of water into closely fitted surfaces. The presence of aggressive ions such as chloride often creates extensive localized attack [4]. Chloride ions are drawn into the crevice as metal dissolution occurs and the conditions inside the crevice become acidic. Metals like aluminum that depend on oxide films or passive layers for corrosion resistance are particularly susceptible to crevice corrosion. Attack from this phenomenon can be aggravated when combined with the presence of crystalline defect such as $\mathrm{Mg}_{2} \mathrm{Si}$ precipitates. Possibility exists for reducing drastically the alloy susceptibility to corrosion if its microstructure is modified by appropriate heat treatment prior to usage. In this study, the chemical response of heattreated aluminium-magnesium alloy in chloride and acidic media was investigated.

\section{Experimental Procedure}

2.1. Materials. Ingots of 6063 aluminum alloy and magnesium used for this study were obtained from the Nigerian Aluminum Extrusion Company (NIGALEX). Six different compositions of Al-Mg alloy with chemical compositions shown in Table 1 were produced. The $\mathrm{Mg}$ in the alloy was varied between 0.40 and 2.0 percent.

The aluminum and magnesium alloy ingots were charged together into a crucible pot, heated to molten state, and then poured into a metal mould. Sufficient time was allowed for the cooling of cast samples prior to removal. Each cast sample was divided into sets $A\left(a_{i}-a_{1}\right)$ and $B\left(b_{i}-b_{l}\right)$ with set A samples left untreated while set B samples were retrogressed and aged (RRA). The samples in solution were heat treated at $475^{\circ} \mathrm{C}$ and aged for $24 \mathrm{hrs}$ (T6 condition) after which the samples were retrogressed at $200^{\circ} \mathrm{C}$, held for forty minutes, and quenched in water. The RRA samples were then tempered at $120^{\circ} \mathrm{C}$ for $24 \mathrm{hrs}$ and allowed to cool in air.

Standard electrochemical corrosion coupons (Figure 1) and microstructural test specimens were prepared from both sets A and B samples. For electrochemical and gravimetric tests, $\varnothing 10 \mathrm{~mm} \times 60 \mathrm{~mm}$ cylindrical rods and circular samples with dimensions of $\varnothing 14 \mathrm{~mm} \times 4 \mathrm{~mm}$ were used, respectively.

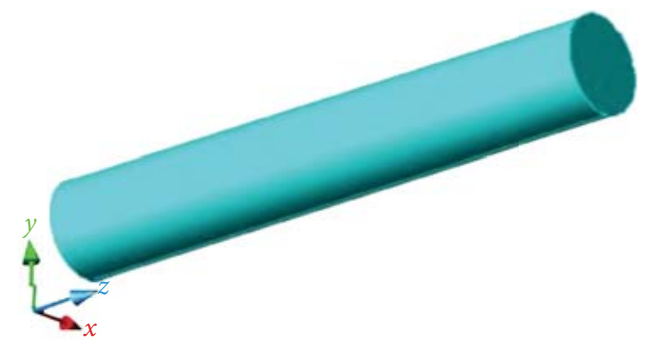

Figure 1: Standard electrochemical corrosion specimen.

2.2. Corrosion Campaigns. The corrosion simulations were carried out on the RRA specimens using electrochemical polarization and gravimetric techniques in three different media, namely, salt, ferric chloride, and acid. Immersion test simulates corrosion resistance of alloy in chloride environment containing $10 \%$ salt in water saturated with oxygen at room temperature. The ferric chloride test is used to study the responses of $\mathrm{Al}-\mathrm{Mg}$ alloy to crevice corrosion in a medium consisting of $5.6 \mathrm{~mL}$ of $\mathrm{FeCl}_{3} \cdot 6 \mathrm{H}_{2} \mathrm{O}, 2 \mathrm{~g}$ of $\mathrm{NaCl}$, and $5 \mathrm{~g}$ of concentrated $\mathrm{HCl}$ in $300 \mathrm{~mL}$ of water. $\mathrm{EXCO}$ test studies exfoliation corrosion of $\mathrm{Al}-\mathrm{Mg}$ alloy in severe industrial or marine environments containing $5 \mathrm{~g}$ of $\mathrm{NaCl}$, $5 \mathrm{~g}$ of $\mathrm{KNO}_{3}$, and $9 \mathrm{~mL}$ of $\mathrm{HNO}_{3}$ in $300 \mathrm{~mL}$ of water. The Jenway 350-pH device was used to determine the $\mathrm{pH}$ of $\mathrm{NaCl}$, $\mathrm{FeCl}_{3}$, and EXCO solutions and the values are 6.80, 6.20, and 6.03 , respectively.

In the gravimetric corrosion test, the initial weights of the test specimens were recorded before immersion in the test media while change in weights was taken every week using a Mettler Toledo weighing scale after the test pieces were rinsed in water and air-dried. The electrochemical corrosion setup (Figure 2(a)) is similar to electrolytic process in which the aluminum-magnesium alloy coupon and copper act as anode and cathode electrodes, respectively. The electrodes were partially immersed in the media in separate containers as the anode coupon was connected to the positive terminal of a $12 \mathrm{~V}$ SMF 5219 battery while the copper electrode was connected to its negative terminal and a YEM 2210 variable resistor (Rheostat) was incorporated into the circuit. The drop in current flowing through the system was recorded at 20-minute interval using YEM 2011 ammeter (Figure 2(b)). 


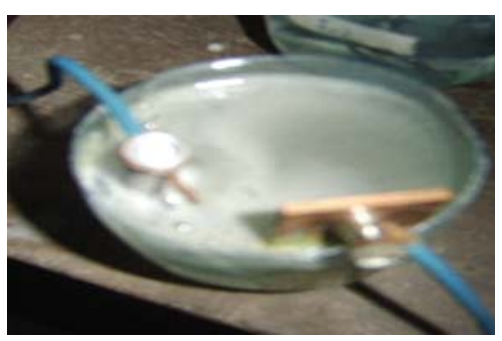

(a)

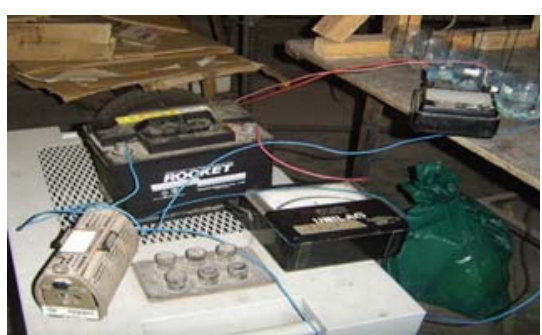

(b)

FIGURE 2: Electrochemical setup. Electrical measuring devices

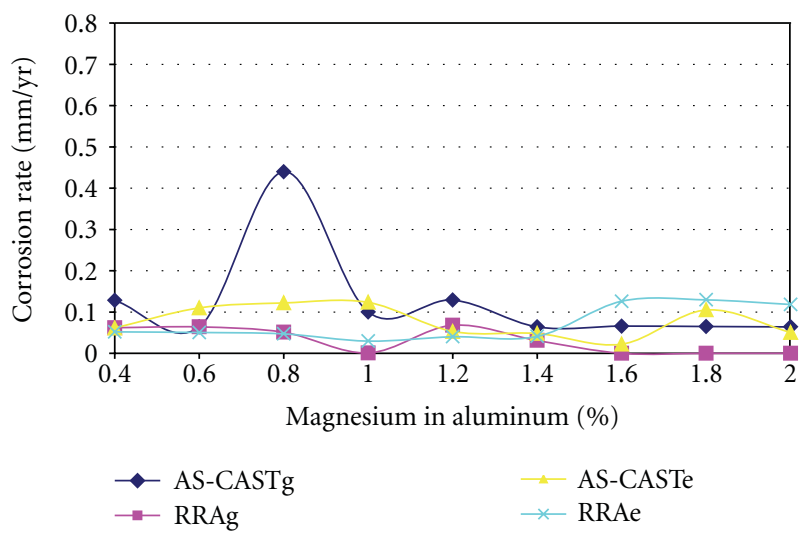

FIGURE 3: Effect of magnesium addition on the corrosion resistance of aluminum alloy in $\mathrm{NaCl}$ solution. Note: RRAg and AS-CASTg curves indicate the corrosion responses of heat-treated as-cast Al$\mathrm{Mg}$ alloy specimens, respectively, in saline medium as evaluated through the gravimetric technique while RRAe and AS-CASTe curves illustrate the corrosion behaviors of heat-treated and ascast $\mathrm{Al}-\mathrm{Mg}$ alloy specimens, respectively, in saline environment as evaluated through the electrochemical polarization technique.

This electrochemical corrosion process lasted for six hours for each test piece studied.

2.3. Microstructure Analysis. Test specimens were prepared from the alloy samples and ground using emery grades of $40,32,10$, and 8 in succession. The ground surfaces were polished using alumina paste to obtain a mirror-like surface. The polished test pieces were etched using dilute hydrochloric acid for 10s. The etched surfaces were carefully washed and dried. A digital Metallurgical Microscope at magnification of $\times 100$ was used to obtain the morphology of the sample matrix, while the photomicrographs produced from these test specimens are shown in Figures 6-11.

\section{Results and Discussion}

3.1. Corrosion Rate Measurements. The corrosion susceptibility of test specimens in the various media $\left(\mathrm{NaCl}, \mathrm{FeCl}_{3}\right.$, and EXCO solution) simulated was evaluated through both the gravimetric and electrochemical polarization techniques. This was carried out for the purposes of comparing which method can quickly provide information on the extent of corrosion on one hand and reliability of the data obtained on the other. Gravimetric corrosion measurement technique basically bothered on weight-loss regime of test specimens. In applying this method, the weights of test specimens were obtained before and at the end of time specified for each monitoring phase. Before the next phase of monitoring, the test specimens were thoroughly washed with water, air-dried, and weighed. The weight-loss data (Appendix A.1) obtained was used to compute the corrosion rate making use of the following relation:

$$
\text { corrosion rate }(\mathrm{mm} / \mathrm{yr})=\frac{87.6 \mathrm{~W}}{\rho A t},
$$

where $W$ is weight-loss ( $\mathrm{mg}), \rho$ density of test specimen $\left(\mathrm{gcm}^{-3}\right), A$ area of test specimen $\left(\mathrm{cm}^{2}\right)$, and $t$ exposure time (hr).

Electrochemical corrosion evaluation technique makes use of the electrical resistance property of test alloy by measuring the electrical polarization when current is impressed. In this study, standard test coupons of Al-Mg alloy of varying compositions were used as anode while copper was used as cathode. The set-up was partially immersed in each medium separately, and the drop in current flowing in through the system was recorded at 20-minutes interval. The corrosion rates as evaluated through (2) were presented in Appendix A.2.

$$
\text { corrosion rate }(\mathrm{mm} / \mathrm{yr})=\frac{3272 W I_{\text {corr }}}{\rho A},
$$

where $W$ is weight loss (g), $\rho$ density of test specimen $\left(\mathrm{gcm}^{-3}\right), A$ exposure surface area of test specimen $\left(\mathrm{cm}^{2}\right)$, and $I_{\text {corr }}$ current flowing in the test specimen (anode coupon).

The analyses of corrosion behaviour of test specimens by both gravimetric and electrochemical polarization show that the as-cast samples exhibited higher corrosion susceptibility than RRA specimens after immersion in $\mathrm{NaCl}$ solution (Figure 3 ). This trend subsists up to about $1.7 \% \mathrm{Mg}$ addition in the aluminum alloy. The peak corrosion response of AS-CASTg: $0.13 \mathrm{~mm} / \mathrm{yr}$ occurred at $0.4 \%$ and $1.2 \% \mathrm{Mg}$ by gravimetric method while the electrochemical polarization technique recorded RRAe: $0.12 \mathrm{~mm} / \mathrm{yr}$ at $0.91 \%$ and $1.81 \%$ $\mathrm{Mg}$, respectively. In contrast to this observation, the RRA sample did not experience any appreciable corrosion within the period monitored (42 days) as computed using gravimetric technique. Through electrochemical polarization, 


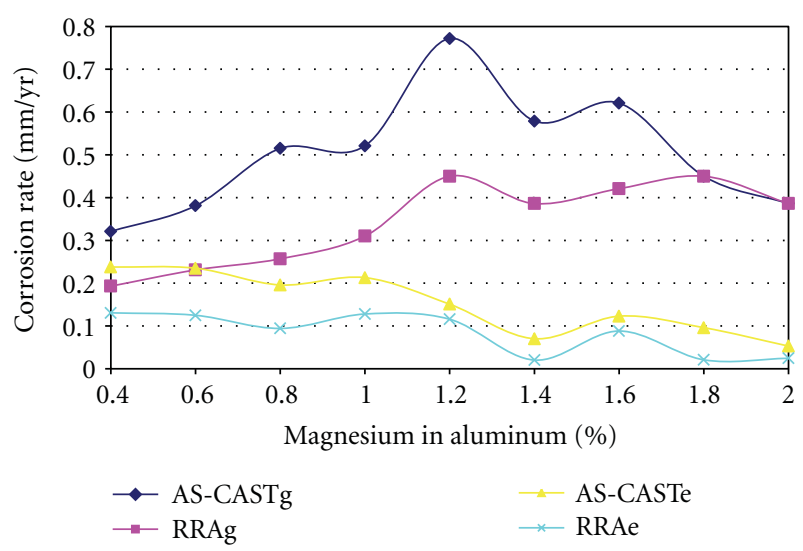

FIGURE 4: Effect of magnesium addition on the corrosion resistance of aluminum alloy in $\mathrm{FeCl}_{3}$ solution. Note: RRAg and AS-CASTg curves indicate the corrosion responses of heat-treated and ascast $\mathrm{Al}-\mathrm{Mg}$ alloy specimens, respectively, in ferric chloride solution as evaluated through the gravimetric technique while RRAe and AS-CASTe curves illustrate the corrosion behaviors of heat-treated and as-cast Al-Mg alloy specimens, respectively, in ferric chloride solution as evaluated through the electrochemical polarization technique.

however, the RRA test coupons exhibited some level of corrosion at $0.13 \mathrm{~mm} / \mathrm{yr}$ for $1.5-2.02 \% \mathrm{Mg}$. The corrosion responses of the RRA test specimens in saline environment which contrast those of as-cast specimens can be attributed to the extensive microstructure evolution that occurred during heat treatment. The grains are relieved, refined, and homogenized. However, at higher magnesium addition, 1.2$2.02 \%$, the corresponding high volume of $\mathrm{Mg}_{2}$ Si precipitated adversely impacted the alloys corrosion resistance.

The curves in Figure 4 illustrate the corrosion behavior of test specimens in ferric chloride environment. With regard to gravimetric corrosion measurement, the as-cast specimens show increasing corrosion propensity, AS-CASTg: 0.321$0.772 \mathrm{~mm} / \mathrm{yr}$ for $0.42-1.23 \% \mathrm{Mg}$ addition. Afterwards, the corrosion rate (AS-CASTg) dropped to $0.579 \mathrm{~mm} / \mathrm{yr}$ for $1.51 \% \mathrm{Mg}$ while some level of passivity was displayed at $1.81 \% \mathrm{Mg}$ having just $0.45 \mathrm{~mm} / \mathrm{yr}$ corrosion rate.

The rather sporadic corrosion pattern of the as-cast specimens is due largely to their microstructure inhomogeneity. This is confirmed by the RRAg: $0.45 \mathrm{~mm} / \mathrm{yr}$ maximum corrosion rate by the RRA specimens because their microstructures have been refined by heat treatment.

The corrosion responses of as-cast and RRA samples in ferric chloride solution using electrochemical polarization technique measurement are also presented in Figure 4. Both the as-cast and RRA test coupons demonstrated similar corrosion rate pattern. Corrosion was more prevalent, ASCASTe: $0.151-0.238 \mathrm{~mm} / \mathrm{yr}$ and RRAe: $0.094-0.131 \mathrm{~mm} / \mathrm{yr}$ for as-cast and RRA specimens, respectively, at a relatively low magnesium addition, $0.42-1.23 \%$. However, at a relatively higher magnesium addition, $1.51-2.02 \%$, corrosion rates dropped significantly to $0.053-0.056 \mathrm{~mm} / \mathrm{yr}$ for ascast and $0.020-0.025 \mathrm{~mm} / \mathrm{yr}$ for RRA test coupons. Given this scenario, the electrochemical polarization corrosion

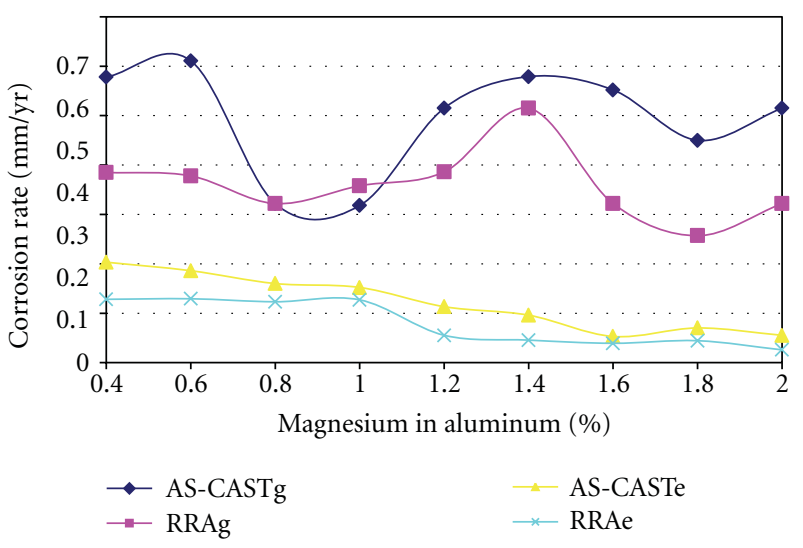

FIGURE 5: Effect of magnesium addition on the corrosion resistance of aluminum alloy in EXCO solution. Note: RRAg and AS-CASTg curves indicate the corrosion responses of heat-treated and as-cast Al-Mg alloy specimens, respectively, in EXCO solution as evaluated through the gravimetric technique while RRAe and AS-CASTe curves illustrate the corrosion behaviors of heat-treated and as-cast $\mathrm{Al}-\mathrm{Mg}$ alloy specimens, respectively, in EXCO solution as evaluated through the electrochemical polarization technique.

measurement has proved that there is a strong correlation between the alloy structural integrity and corrosion susceptibility.

Figure 5 depicts the responses of test coupons to exfoliation corrosion under severe industrial and marine conditions (EXCO). Using the electrochemical polarization technique, the corrosion behaviors of both the as-cast and RRA samples are relatively low and nonuniform, AS-CASTe: 0.055$0.113 \mathrm{~mm} / \mathrm{yr}$ and RRAe: $0.023-6-0.055 \mathrm{~mm} / \mathrm{yr}$ for the as-cast and RRA specimens, respectively.

The inhomogeneity of microstructure must have been responsible for the wide range in corrosion rates exhibited by the as-cast specimens. Evaluation of the corrosion rates on the as-cast specimens through gravimetric method also shows that corrosion is nonuniform and the values are relatively high, AS-CASTg: $0.579 \mathrm{~mm} / \mathrm{yr}$ and $0.322 \mathrm{~mm} / \mathrm{yr}$ being the minimum. The RRA specimens, however, exhibited relatively uniform corrosion rates, RRAg: $0.257-0.386 \mathrm{~mm} / \mathrm{yr}$ for the various magnesium additions. This is due to structural modifications that occurred pursuant to the heat treatment carried out on the alloy.

The microstructure of the as-cast specimens (Figure $\left.6\left(\mathrm{a}_{\mathrm{i}}\right)\right)$ shows phases that are not evenly dispersed in the $\alpha$ aluminum matrix, while there is strong clustering of $\mathrm{Mg}_{2} \mathrm{Si}$ in certain area of the matrix. This is a potential polarization site for electrochemical attack on the alloy. The RRA specimens however have their $\mathrm{Mg}_{2} \mathrm{Si}$ crystals fairly distributed within the matrix (Figure $6\left(b_{i}\right)$ ).

Dipping of these specimens in $\mathrm{NaCl}$ solution gave rise to a substantial depletion of crystals of $\mathrm{Mg}_{2} \mathrm{Si}$ and other intermetallics. This observation was more pronounced in the as-cast specimens (Figures $\left.6\left(a_{j}\right), 6\left(b_{j}\right)\right)$ while the RRA alloy exhibited higher resistance to corrosion in $\mathrm{NaCl}$ solution than in $\mathrm{FeCl}_{3}$ (Figures $6\left(\mathrm{~b}_{\mathrm{j}}\right), 6\left(\mathrm{~b}_{\mathrm{k}}\right)$ ). In EXCO solution, the clustering arrangement of $\mathrm{Mg}_{2} \mathrm{Si}$ crystals was preserved in 


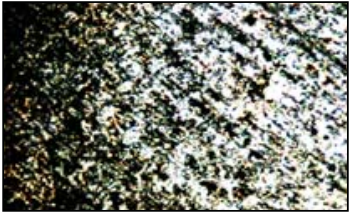

$\left(a_{i}\right)$ As-cast $\alpha$-aluminum matrix

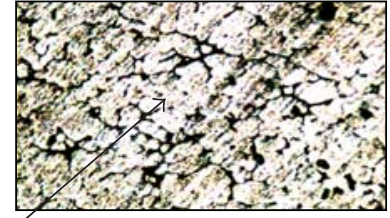

$\left(a_{j}\right)$ As-cast in $\mathrm{NaCl}$

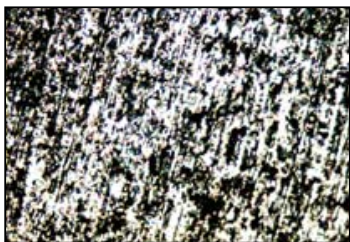

( $\left.b_{i}\right)$ RRA

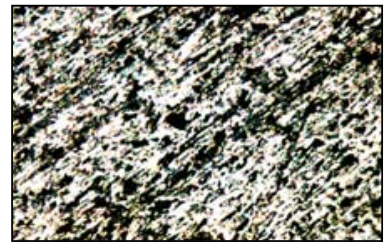

$\left(b_{j}\right)$ RRA in $\mathrm{NaCl}$

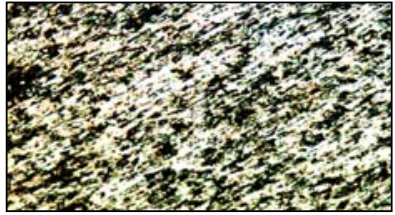

$\left(a_{\mathrm{k}}\right)$ As-cast in $\mathrm{FeCl}_{3}$

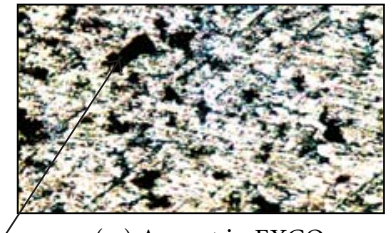

(al) As-cast in EXCO

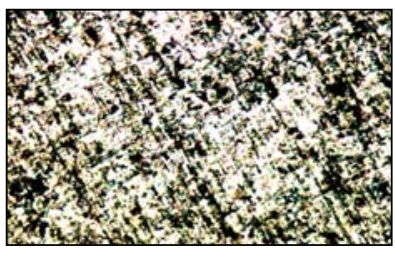

(b $b_{k}$ RRA in $\mathrm{FeCl}_{3}$

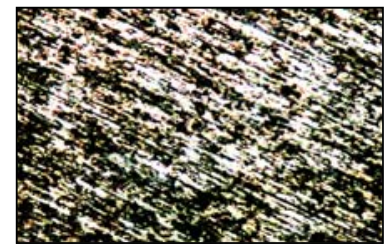

(bl) RRA in EXCO

Figure 6: Micrographs of $0.42 \% \mathrm{Mg}$ addition for untreated $\left(\mathrm{a}_{\mathrm{i}}-\mathrm{a}_{1}\right)$ and treated $\left(\mathrm{b}_{\mathrm{i}}-\mathrm{b}_{\mathrm{l}}\right)$ specimens.

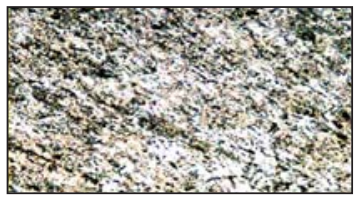

$\left(\mathrm{a}_{\mathrm{i}}\right)$ As-cast

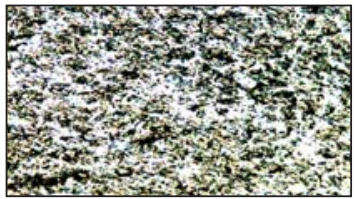

$\left(b_{i}\right)$ RRA

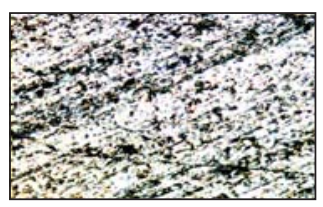

$\left(\mathrm{a}_{\mathrm{j}}\right)$ As-cast in $\mathrm{NaCl}$

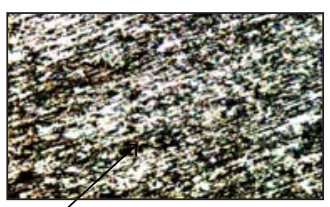

$\left(a_{\mathrm{k}}\right)$ As-cast in $\mathrm{FeCl}_{3}$

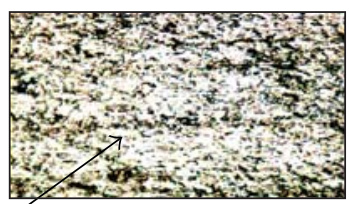

(al) As-cast in EXCO $\alpha$-aluminum matrix

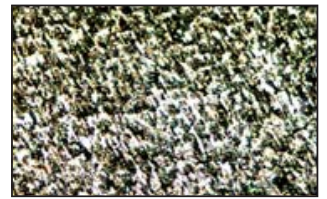

$\left(b_{j}\right)$ RRA in $\mathrm{NaCl}$

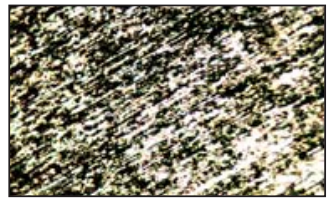

$\left(b_{\mathrm{k}}\right)$ RRA in $\mathrm{FeCl}_{3}$

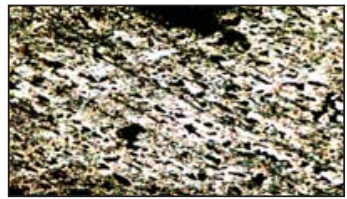

(bl) RRA in EXCO

Figure 7: Micrographs of $0.91 \% \mathrm{Mg}$ addition for untreated $\left(\mathrm{a}_{\mathrm{i}}-\mathrm{a}_{1}\right)$ and treated $\left(\mathrm{b}_{\mathrm{i}}-\mathrm{b}_{1}\right)$ specimens.

both alloy specimens (Figures $\left.6\left(a_{1}\right), 6\left(b_{1}\right)\right)$ but the depletion of other intermetallics in the as-cast specimens was more than those of RRA alloy specimens. At $0.9 \% \mathrm{Mg}$ addition, both alloy specimens have a fairly high volume fraction of $\mathrm{Mg}_{2} \mathrm{Si}$ precipitates present in the matrices (Figures $7\left(\mathrm{a}_{\mathrm{i}}\right)$, $7\left(b_{\mathrm{i}}\right)$ ). On immersion in $\mathrm{NaCl}$ solution, the as-cast matrix is strongly attacked with significant erosion of the intermetallic phases while the RRA specimens show superior resistance to attack (Figures $7\left(a_{k}\right), 7\left(b_{j}\right)$.

Both the precipitates and intermetallic phases, however, remain stable in $\mathrm{FeCl}_{3}$ solution (Figures $7\left(\mathrm{a}_{\mathrm{k}}\right), 7\left(\mathrm{~b}_{\mathrm{k}}\right)$ ) while erosion of magnesium silicides was observed with the as-cast alloy in EXCO solution (Figures $7\left(a_{1}\right), 7\left(b_{1}\right)$ ). Fine crystals of magnesium silicides made appearance at $1.2 \% \mathrm{Mg}$ addition (Figures $8\left(\mathrm{a}_{\mathrm{i}}\right), 8\left(\mathrm{~b}_{\mathrm{i}}\right)$ ).

The crystals remain stable in the matrices of both alloys when dipped in $\mathrm{NaCl}$ solution (Figures $\left.8\left(\mathrm{a}_{\mathrm{j}}\right), 8\left(\mathrm{~b}_{\mathrm{j}}\right)\right)$. In $\mathrm{FeCl}_{3}$ solution, however, severe erosion of the intermetallic crystals which is more pronounced in as-cast matrix was observed (Figures $8\left(a_{k}\right), 8\left(b_{k}\right)$ ) while the response of both specimens was not quite apparent in EXCO solution (Figures $8\left(\mathrm{a}_{1}\right)$, $\left.8 b_{1}\right)$ ). In Figure 9, the aluminum alloy specimens that contain
$1.5 \% \mathrm{Mg}$ have fine crystals induced in their structure (Figures $\left.9\left(a_{i}\right), 9\left(b_{i}\right)\right)$. The intermetallic phase in the RRA alloy matrix was severely eroded in $\mathrm{NaCl}$ solution leaving the $\mathrm{Mg}_{2} \mathrm{Si}$ crystals intact (Figures $9\left(a_{j}\right), 9\left(b_{j}\right)$ ). However in $\mathrm{FeCl}_{3}$, the corrosion behaviour of as-cast specimens is similar to that of RRA specimens, and $\mathrm{Mg}_{2} \mathrm{Si}$ phase shows more resistance than other intermetallics (Figures $9\left(a_{k}\right), 9\left(b_{k}\right)$ ). In Figures $9\left(a_{1}\right), 9\left(b_{1}\right)$ the as-cast alloy was strongly attacked in EXCO solution while substantial volume of $\mathrm{Mg}_{2} \mathrm{Si}$ crystals induced in RRA specimens was retained.

In Figures $10\left(a_{i}\right), 10\left(b_{i}\right)$, higher volume fraction of intermetallics was observed in as-cast structure while clustering of $\mathrm{Mg}_{2} \mathrm{Si}$ crystals occurred in RRA specimens. When immersed in $\mathrm{NaCl}$ solution, the as-cast matrix significantly corroded leaving only a few traces of the intermetallic crystals. The RRA suffered serious attack of its crystals than as-cast specimens in $\mathrm{FeCl}_{3}$ solution with $\mathrm{Mg}_{2} \mathrm{Si}$ crystals been washed off along with other intermetallics.

In EXCO solution, considerable corrosion occurred in the as-cast specimens thereby leaving the matrix almost bare (Figure 10 $\left(\mathrm{a}_{1}\right)$ ). The RRA alloy matrix, however, exhibited resistance to corrosion in EXCO solution, but, significant 


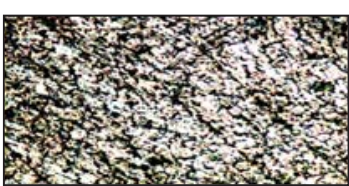

(ai $)$ As-cast

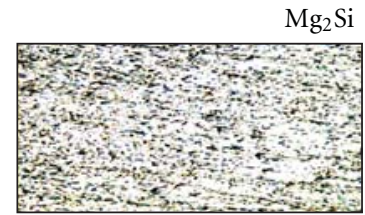

(bi $b_{i}$ RRA

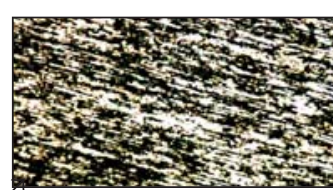

$\left(a_{j}\right)$ As-cast in $\mathrm{NaCl}$
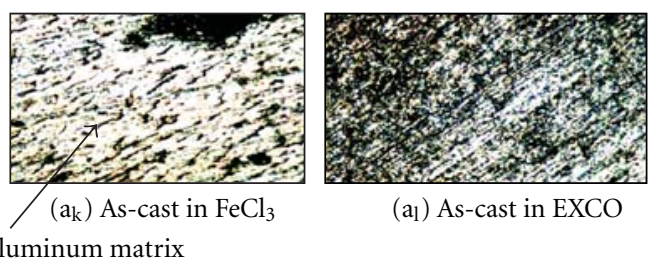

(al) As-cast in EXCO

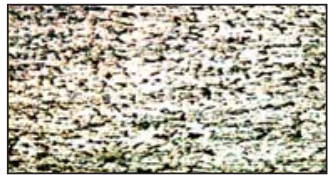

$\left(b_{j}\right)$ RRA in $\mathrm{NaCl}$

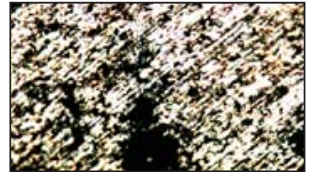

$\left(b_{\mathrm{k}}\right)$ RRA in $\mathrm{FeCl}_{3}$

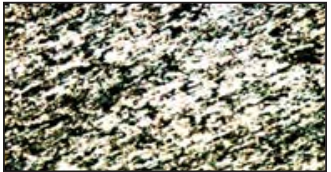

$\left(b_{1}\right)$ RRA in EXCO

Figure 8: Micrographs of $1.23 \% \mathrm{Mg}$ addition for untreated $\left(\mathrm{a}_{\mathrm{i}}-\mathrm{a}_{1}\right)$ and treated $\left(\mathrm{b}_{\mathrm{i}}-\mathrm{b}_{1}\right)$ specimens.

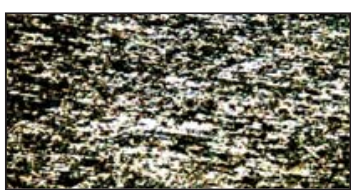

$\left(\mathrm{a}_{\mathrm{i}}\right)$ As-cast

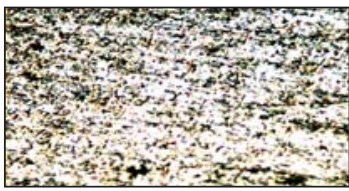

(bi) RRA

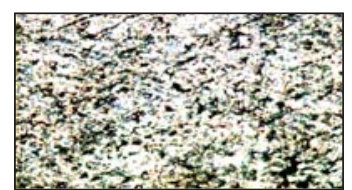

$\left(a_{j}\right)$ As-cast in $\mathrm{NaCl}$

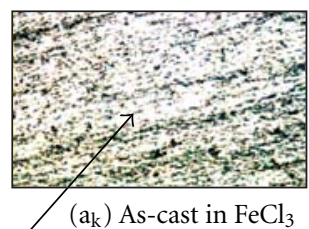

$\alpha$-aluminum matrix

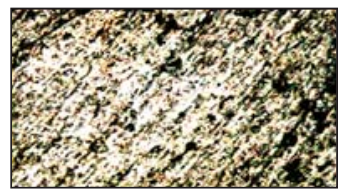

$\left(b_{j}\right)$ RRA in $\mathrm{NaCl}$

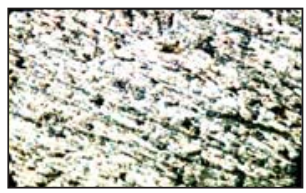

$\left(b_{\mathrm{k}}\right)$ RRA in $\mathrm{FeCl}_{3}$
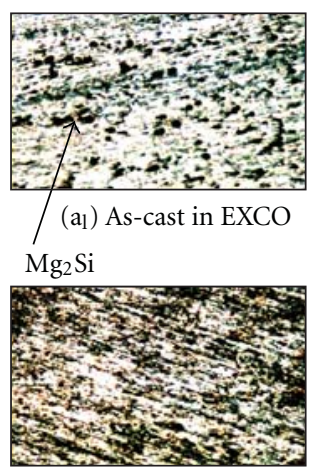

(bl) RRA in EXCO

FIgURE 9: Micrographs of $1.51 \% \mathrm{Mg}$ addition for untreated $\left(\mathrm{a}_{\mathrm{i}}-\mathrm{a}_{1}\right)$ and treated $\left(\mathrm{b}_{\mathrm{i}}-\mathrm{b}_{1}\right)$ specimens.

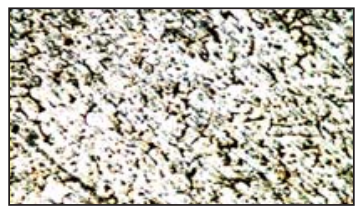

$\left(\mathrm{a}_{\mathrm{i}}\right)$ As-cast

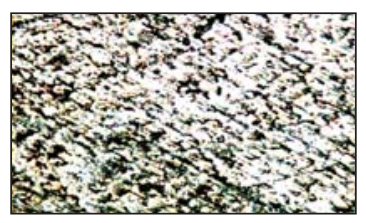

$\left(b_{i}\right)$ RRA

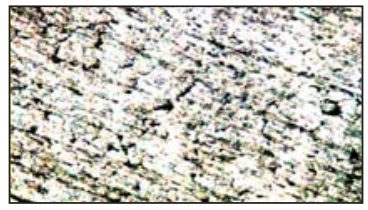

$\left(\mathrm{a}_{\mathrm{j}}\right)$ As-cast in $\mathrm{NaCl}$

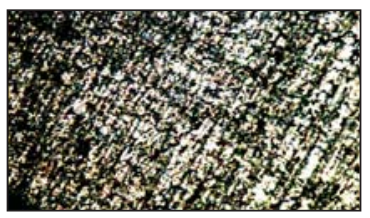

$\left(b_{j}\right)$ RRA in $\mathrm{NaCl}$

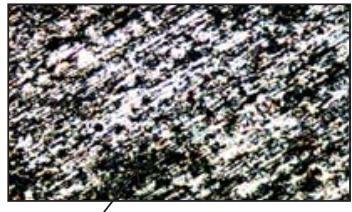

$\left(\mathrm{a}_{\mathrm{k}}\right)$ As-cast in $\mathrm{FeCl}_{3}$ $\mathrm{Mg}_{2} \mathrm{Si}$

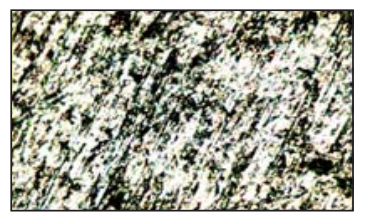

$\left(b_{\mathrm{k}}\right)$ RRA in $\mathrm{FeCl}_{3}$

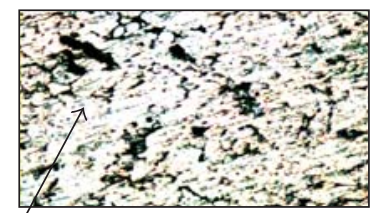

(al) As-cast in EXCO $\alpha$-aluminum matrix

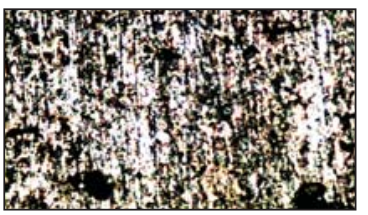

(bl) RRA in EXCO

FIgURE 10: Micrographs of $1.81 \% \mathrm{Mg}$ addition for untreated $\left(\mathrm{a}_{\mathrm{i}}-\mathrm{a}_{1}\right)$ and treated $\left(\mathrm{b}_{\mathrm{i}}-\mathrm{b}_{1}\right)$ specimens.

amount of $\mathrm{Mg}_{2} \mathrm{Si}$ crystals was eroded leaving pit-like features in the matrix. (Figure $10\left(b_{1}\right)$ ).

Figure 11 shows low volume fractions of $\mathrm{Mg}_{2} \mathrm{Si}$ crystals in the RRA specimens at $2.0 \% \mathrm{Mg}$ addition (Figure $11\left(\mathrm{~b}_{\mathrm{i}}\right)$ ). Strong erosion of the $\mathrm{Mg}_{2} \mathrm{Si}$ crystals occurred in the ascast matrix when dipped in $\mathrm{NaCl}$ solution but the other intermetallics were resistant in this medium (Figures $11\left(\mathrm{a}_{\mathrm{j}}\right)$, $\left.11\left(b_{j}\right)\right)$. In $\mathrm{FeCl}_{3}$ solution, the intermetallics show resistance to attack in both as-cast and RRA matrices but suffered the loss of crystals of $\alpha$-aluminum to corrosion (Figures $11\left(\mathrm{a}_{\mathrm{k}}\right)$, $\left.11\left(b_{k}\right)\right)$. Immersion of the alloy specimens in EXCO solution resulted in severe attack on the crystals of RRA matrix while the intermetallics in as-cast show superior resistance to the crystals of $\alpha$-aluminum in this medium (Figures $11\left(a_{1}\right)$, $\left.11\left(b_{1}\right)\right)$.

\section{Conclusion}

Corrosion responses of the as-cast and RRA alloy specimens differ significantly based on the microstructure induced in 


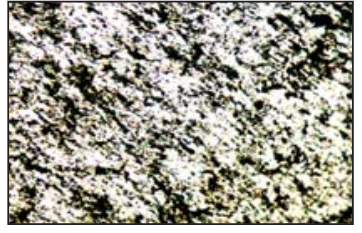

$\left(\mathrm{a}_{\mathrm{i}}\right)$ As-cast

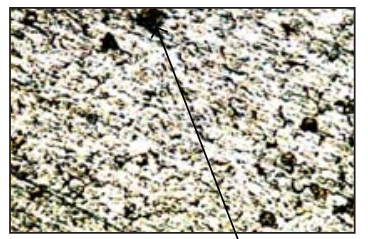

$\left(b_{i}\right)$ RRA $\mathrm{Mg}_{2} \mathrm{Si}$

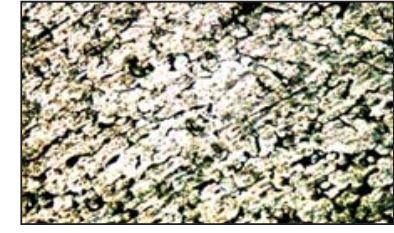

$\left(a_{j}\right)$ As-cast in $\mathrm{NaCl}$

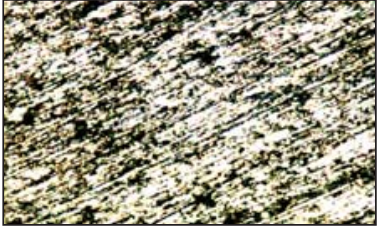

$\left(b_{j}\right) R R A$ in $\mathrm{NaCl}$

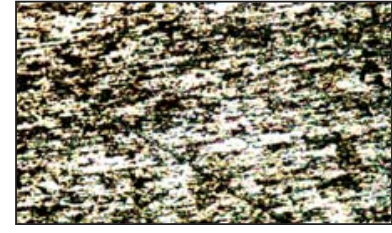

$\left(\mathrm{a}_{\mathrm{k}}\right)$ As-cast in $\mathrm{FeCl}_{3}$

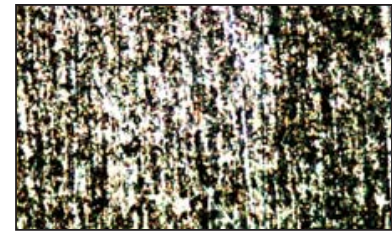

$\left(b_{k}\right)$ RRA in $\mathrm{FeCl}_{3}$

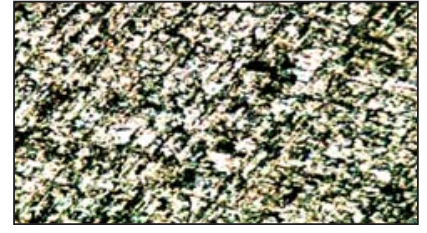

(al) As-cast in EXCO

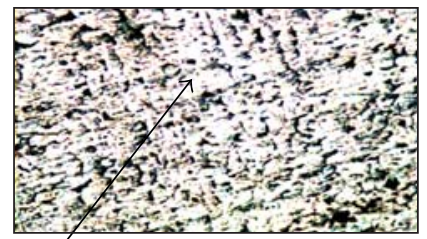

(bl) RRA in EXCO

Figure 11: Micrographs of $2.02 \%$ Mg addition for untreated $\left(a_{i}-a_{1}\right)$ and treated $\left(b_{i}-b_{1}\right)$ specimens.

TABLe 2: Gravimetric corrosion rate $(\mathrm{mm} / \mathrm{yr})$ for the $0.42 \% \mathrm{Mg}$ specimen.

\begin{tabular}{lcccccc}
\hline \multirow{2}{*}{ Days } & \multicolumn{2}{c}{$\mathrm{NaCl}$ solution } & \multicolumn{2}{c}{$\mathrm{FeCl}_{3}$} & \multicolumn{2}{c}{ EXCO solution } \\
& As-cast & RRA & As-cast & RRA & As-cast & RRA \\
\hline 0 & 0 & 0 & 0 & 0 & 0 & 0 \\
7 & 0 & 0 & 0.385 & 0 & 0.381 & 0.385 \\
14 & 0 & 0 & 0.385 & 0.193 & 0.578 & 0.193 \\
21 & 0 & 0 & 0.385 & 0.128 & 0.514 & 0.257 \\
28 & 0.096 & 0 & 0.289 & 0.193 & 0.578 & 0.385 \\
35 & 0.077 & 0 & 0.308 & 0.231 & 0.617 & 0.385 \\
42 & 0.128 & 0.064 & 0.321 & 0.193 & 0.578 & 0.385 \\
\hline
\end{tabular}

TABle 3: Gravimetric corrosion rate $(\mathrm{mm} / \mathrm{yr})$ for the $0.91 \% \mathrm{Mg}$ specimen.

\begin{tabular}{lcccccc}
\hline \multirow{2}{*}{ Days } & \multicolumn{2}{c}{$\mathrm{NaCl}$ solution } & \multicolumn{2}{c}{$\mathrm{FeCl}_{3}$} & \multicolumn{2}{c}{ EXCO solution } \\
& As-cast & RRA & As-cast & RRA & As-cast & RRA \\
\hline 0 & 0.000 & 0.000 & 0.000 & 0.000 & 0.000 & 0.000 \\
1200 & 0.000 & 0.000 & 0.771 & 0.000 & 0.000 & 0.000 \\
2400 & 0.000 & 0.000 & 0.771 & 0.193 & 0.193 & 0.193 \\
3600 & 0.000 & 0.000 & 0.642 & 0.257 & 0.128 & 0.257 \\
4800 & 0.000 & 0.000 & 0.578 & 0.289 & 0.193 & 0.385 \\
6000 & 0.077 & 0.000 & 0.54 & 0.231 & 0.231 & 0.308 \\
7200 & 0.064 & 0.000 & 0.515 & 0.257 & 0.322 & 0.322 \\
\hline
\end{tabular}

them. The precipitated $\mathrm{Mg}_{2} \mathrm{Si}$ crystals are anodic relative to the alloy matrix which easily dissolved under attack by chemical. This phenomenon occurred at relatively higher magnesium content in the range of $1.2-2.0 \%$. Within this range, the volume fraction of $\mathrm{Mg}_{2} \mathrm{Si}$ precipitates in the alloy matrix is rather substantial thereby accentuating susceptibility to corrosion.

Heat treatment process employed in this study serves the purpose of modifying the alloy microstructure such that
TABLE 4: Gravimetric corrosion rate $(\mathrm{mm} / \mathrm{yr}$ ) for the $1.23 \% \mathrm{Mg}$ specimen.

\begin{tabular}{lcccccc}
\hline \multirow{2}{*}{ Days } & \multicolumn{2}{c}{$\mathrm{NaCl}$ solution } & \multicolumn{2}{c}{$\mathrm{FeCl}_{3}$} & \multicolumn{2}{c}{ EXCO Solution } \\
& As-cast & RRA & As-cast & RRA & As-cast & RRA \\
\hline 0 & 0.000 & 0.000 & 0.000 & 0.000 & 0.000 & 0.000 \\
7 & 0.000 & 0.000 & 1.542 & 0.771 & 0.000 & 0.385 \\
14 & 0.000 & 0.000 & 1.156 & 0.771 & 0.385 & 0.385 \\
21 & 0.128 & 0.000 & 1.028 & 0.514 & 0.514 & 0.514 \\
28 & 0.096 & 0.000 & 0.963 & 0.482 & 0.482 & 0.482 \\
35 & 0.154 & 0.000 & 0.848 & 0.463 & 0.540 & 0.463 \\
42 & 0.129 & 0.064 & 0.772 & 0.450 & 0.515 & 0.386 \\
\hline
\end{tabular}

TABLE 5: Gravimetric corrosion rate $(\mathrm{mm} / \mathrm{yr}$ ) for the $1.51 \% \mathrm{Mg}$ specimen.

\begin{tabular}{lcccccc}
\hline \multirow{2}{*}{ Days } & \multicolumn{2}{c}{$\mathrm{NaCl}$ solution } & \multicolumn{2}{c}{$\mathrm{FeCl}_{3}$} & \multicolumn{2}{c}{ EXCO solution } \\
& As-cast & RRA & As-cast & RRA & As-cast & RRA \\
\hline 0 & 0.000 & 0.000 & 0.000 & 0.000 & 0.000 & 0.000 \\
7 & 0.000 & 0.000 & 1.156 & 1.156 & 0.771 & 0.000 \\
14 & 0.000 & 0.000 & 0.964 & 0.578 & 0.578 & 0.385 \\
21 & 0.000 & 0.000 & 0.899 & 0.385 & 0.642 & 0.514 \\
28 & 0.000 & 0.000 & 0.771 & 0.385 & 0.578 & 0.482 \\
35 & 0.077 & 0.000 & 0.694 & 0.385 & 0.54 & 0.463 \\
42 & 0.064 & 0.000 & 0.579 & 0.386 & 0.579 & 0.515 \\
\hline
\end{tabular}

inducement of soluble precipitates is suppressed in preference to strongly refractory intermetallics. This behavior was observed in the RRA specimens compared with as-cast alloy specimens thereby validating established significant role of the presence of intermetallics in an alloy matrix with respect to corrosion mitigation [15]. Intermetallics are complex compounds which do not easily dissolve thereby becoming cathodic relative to the alloy matrix. Therefore, the extent of corrosion suffered by an alloy depends on which phase 
TABLE 6: Gravimetric corrosion rate $(\mathrm{mm} / \mathrm{yr}$ ) For the $1.81 \% \mathrm{Mg}$ specimen.

\begin{tabular}{lcccccc}
\hline \multirow{2}{*}{ Days } & \multicolumn{2}{c}{$\mathrm{NaCl}$ solution } & \multicolumn{2}{c}{$\mathrm{FeCl}_{3}$} & \multicolumn{2}{c}{ EXCO solution } \\
& As-cast & RRA & As-cast & RRA & As-cast & RRA \\
\hline 0 & 0.000 & 0.000 & 0.000 & 0.000 & 0.000 & 0.000 \\
7 & 0.000 & 0.000 & 0.771 & 0.771 & 0.771 & 0.385 \\
14 & 0.000 & 0.000 & 0.771 & 0.771 & 0.771 & 0.385 \\
21 & 0.000 & 0.000 & 0.642 & 0.514 & 0.514 & 0.385 \\
28 & 0.000 & 0.000 & 0.578 & 0.578 & 0.482 & 0.289 \\
35 & 0.000 & 0.000 & 0.54 & 0.54 & 0.463 & 0.231 \\
42 & 0.000 & 0.000 & 0.45 & 0.45 & 0.45 & 0.257 \\
\hline
\end{tabular}

TABLE 7: Gravimetric corrosion rate $(\mathrm{mm} / \mathrm{yr})$ for the $2.02 \% \mathrm{Mg}$ specimen.

\begin{tabular}{lcccccc}
\hline \multirow{2}{*}{ Days } & \multicolumn{2}{c}{$\mathrm{NaCl}$ solution } & \multicolumn{2}{c}{$\mathrm{FeCl}_{3}$} & \multicolumn{2}{c}{ EXCO Solution } \\
& As-cast & RRA & As-cast & RRA & As-cast & RRA \\
\hline 0 & 0.000 & 0.000 & 0.000 & 0.000 & 0.000 & 0.000 \\
7 & 0.000 & 0.000 & 0.771 & 0.771 & 0.385 & 0.000 \\
14 & 0.000 & 0.000 & 0.385 & 0.771 & 0.578 & 0.193 \\
21 & 0.000 & 0.000 & 0.514 & 0.514 & 0.514 & 0.578 \\
28 & 0.000 & 0.000 & 0.482 & 0.482 & 0.482 & 0.514 \\
35 & 0.077 & 0.000 & 0.463 & 0.385 & 0.54 & 0.308 \\
42 & 0.064 & 0.064 & 0.386 & 0.386 & 0.515 & 0.322 \\
\hline
\end{tabular}

TABLE 8: Gravimetric corrosion rate $(\mathrm{mm} / \mathrm{yr})$ for the control specimen.

\begin{tabular}{lcccccc}
\hline \multirow{2}{*}{ Days } & \multicolumn{2}{c}{$\mathrm{NaCl}$ solution } & \multicolumn{2}{c}{$\mathrm{FeCl}_{3}$} & \multicolumn{2}{c}{ EXCO solution } \\
& As-cast & RRA & As-cast & RRA & As-cast & RRA \\
\hline 0 & 0 & 0 & 0 & 0 & 0 & 0 \\
7 & 0 & 0 & 0.771 & 0.771 & 0.771 & 0.384 \\
14 & 0 & 0 & 0.771 & 0.771 & 0.771 & 0.385 \\
21 & 0.129 & 0 & 0.642 & 0.514 & 0.642 & 0.385 \\
28 & 0.096 & 0 & 0.578 & 0.482 & 0.674 & 0.289 \\
35 & 0.154 & 0.077 & 0.54 & 0.385 & 0.694 & 0.308 \\
42 & 0.193 & 0.192 & 0.45 & 0.386 & 0.643 & 0.322 \\
\hline
\end{tabular}

TABLE 9: Electrochemical corrosion rate For the $0.42 \% \mathrm{Mg}$ specimen.

\begin{tabular}{lcccccc}
\hline \multirow{2}{*}{$T$ (sec) } & \multicolumn{2}{c}{ NaCl solution } & \multicolumn{2}{c}{$\mathrm{FeCl}_{3}$} & \multicolumn{2}{c}{ EXCO solution } \\
& As-cast & RRA & As-cast & RRA & As-cast & RRA \\
\hline 0 & 0.0000 & 0.0000 & 0.0000 & 0.0000 & 0.0000 & 0.0000 \\
1200 & 0.0117 & 0.0123 & 0.0425 & 0.0394 & 0.0370 & 0.0238 \\
2400 & 0.0224 & 0.0238 & 0.0850 & 0.0468 & 0.0727 & 0.0460 \\
3600 & 0.0324 & 0.0338 & 0.1254 & 0.0690 & 0.1072 & 0.0666 \\
4800 & 0.0425 & 0.0443 & 0.1643 & 0.0904 & 0.1429 & 0.0871 \\
6000 & 0.0511 & 0.0544 & 0.1982 & 0.1109 & 0.1725 & 0.1089 \\
7200 & 0.0614 & 0.0520 & 0.2378 & 0.1307 & 0.2033 & 0.1282 \\
\hline
\end{tabular}

TABLE 10: Electrochemical corrosion rate for the $0.91 \% \mathrm{Mg}$ specimen.

\begin{tabular}{lcccccc}
\hline \multirow{2}{*}{$T(\mathrm{sec})$} & \multicolumn{2}{c}{ NaCl solution } & \multicolumn{2}{c}{$\mathrm{FeCl}_{3}$} & \multicolumn{2}{c}{ EXCO solution } \\
& As-cast & RRA & As-cast & RRA & As-cast & RRA \\
\hline 0 & 0.0000 & 0.0000 & 0.0000 & 0.0000 & 0.0000 & 0.0000 \\
1200 & 0.0242 & 0.0061 & 0.0363 & 0.0176 & 0.0308 & 0.0238 \\
2400 & 0.0468 & 0.0117 & 0.0702 & 0.0345 & 0.0605 & 0.04600 \\
3600 & 0.0678 & 0.0167 & 0.1035 & 0.0499 & 0.0877 & 0.0653 \\
4800 & 0.0871 & 0.0214 & 0.1355 & 0.0653 & 0.1129 & 0.0855 \\
6000 & 0.1027 & 0.0252 & 0.1663 & 0.0785 & 0.1360 & 0.01048 \\
7200 & 0.1233 & 0.0296 & 0.1959 & 0.0943 & 0.1601 & 0.1232 \\
\hline
\end{tabular}

TABLe 11: Electrochemical corrosion rate for the $1.23 \% \mathrm{Mg}$ specimen.

\begin{tabular}{lcccccc}
\hline \multirow{2}{*}{$T$ (sec) } & \multicolumn{2}{c}{ NaCl solution } & \multicolumn{2}{c}{$\mathrm{FeCl}_{3}$} & \multicolumn{2}{c}{ EXCO solution } \\
& As-cast & RRA & As-cast & RRA & As-cast & RRA \\
\hline 0 & 0 & 0 & 0 & 0 & 0 & 0 \\
1200 & 0.0115 & 0.0057 & 0.0298 & 0.0234 & 0.0234 & 0.0119 \\
2400 & 0.021 & 0.0105 & 0.0565 & 0.0435 & 0.0435 & 0.0222 \\
3600 & 0.0302 & 0.0148 & 0.0816 & 0.0628 & 0.0616 & 0.0308 \\
4800 & 0.0386 & 0.0185 & 0.1068 & 0.0805 & 0.0805 & 0.0394 \\
6000 & 0.0750 & 0.0216 & 0.1283 & 0.0985 & 0.0965 & 0.0482 \\
7200 & 0.0530 & 0.0401 & 0.1509 & 0.1158 & 0.1133 & 0.0554 \\
\hline
\end{tabular}

TABLE 12: Electrochemical corrosion rate for the $1.51 \% \mathrm{Mg}$ specimen.

\begin{tabular}{lcccccc}
\hline \multirow{2}{*}{$T(\mathrm{sec})$} & \multicolumn{2}{c}{ NaCl solution } & \multicolumn{2}{c}{$\mathrm{FeCl}_{3}$} & \multicolumn{2}{c}{ EXCO solution } \\
& As-cast & RRA & As-cast & RRA & As-cast & RRA \\
\hline 0 & 0 & 0 & 0 & 0 & 0 & 0 \\
1200 & 0.0056 & 0.0287 & 0.0169 & 0.0055 & 0.0226 & 0.0115 \\
2400 & 0.0103 & 0.0524 & 0.0308 & 0.0099 & 0.0411 & 0.021 \\
3600 & 0.0142 & 0.0739 & 0.0425 & 0.0136 & 0.0579 & 0.0283 \\
4800 & 0.0173 & 0.0924 & 0.053 & 0.0165 & 0.0707 & 0.0337 \\
6000 & 0.0195 & 0.1103 & 0.0616 & 0.018 & 0.0842 & 0.04 \\
7200 & 0.0222 & 0.1263 & 0.0702 & 0.0203 & 0.0961 & 0.0456 \\
\hline
\end{tabular}

TAble 13: Electrochemical corrosion rate for the $1.81 \% \mathrm{Mg}$ specimen.

\begin{tabular}{lcccccc}
\hline \multirow{2}{*}{$T(\mathrm{sec})$} & \multicolumn{2}{c}{$\mathrm{NaCl}$ solution } & \multicolumn{2}{c}{$\mathrm{FeCl}_{3}$} & \multicolumn{2}{c}{ EXCO solution } \\
& As-cast & RRA & As-cast & RRA & As-cast & RRA \\
\hline 0 & 0 & 0 & 0 & 0 & 0 & 0 \\
1200 & 0.0172 & 0.0282 & 0.023 & 0.0056 & 0.0172 & 0.0113 \\
2400 & 0.032 & 0.0524 & 0.0411 & 0.0101 & 0.0308 & 0.0201 \\
3600 & 0.0434 & 0.0739 & 0.0579 & 0.0136 & 0.0425 & 0.0277 \\
4800 & 0.0517 & 0.0944 & 0.0723 & 0.0165 & 0.053 & 0.0345 \\
6000 & 0.0585 & 0.1129 & 0.0842 & 0.0185 & 0.0631 & 0.04 \\
7200 & 0.105 & 0.1294 & 0.0961 & 0.0209 & 0.0702 & 0.0444 \\
\hline
\end{tabular}


TABLE 14: Electrochemical corrosion rate for the $2.02 \% \mathrm{Mg}$ specimen.

\begin{tabular}{lcccccc}
\hline \multirow{2}{*}{$T$ (sec) } & \multicolumn{2}{c}{ NaCl solution } & \multicolumn{2}{c}{$\mathrm{FeCl}_{3}$} & \multicolumn{2}{c}{ EXCO solution } \\
& As-cast & RRA & As-cast & RRA & As-cast & RRA \\
\hline 0 & 0 & 0 & 0 & 0 & 0 & 0 \\
1200 & 0.0117 & 0.0242 & 0.0119 & 0.0058 & 0.0117 & 0.0058 \\
2400 & 0.0222 & 0.046 & 0.0226 & 0.0107 & 0.0222 & 0.0107 \\
3600 & 0.034 & 0.0653 & 0.0314 & 0.0151 & 0.032 & 0.0148 \\
4800 & 0.0386 & 0.0838 & 0.0402 & 0.0189 & 0.0419 & 0.0189 \\
6000 & 0.0452 & 0.1027 & 0.0472 & 0.0216 & 0.0493 & 0.0226 \\
7200 & 0.0505 & 0.1183 & 0.053 & 0.0246 & 0.0554 & 0.0259 \\
\hline
\end{tabular}

TABLE 15: Electrochemical corrosion rate for the control specimen.

\begin{tabular}{lcccccc}
\hline \multirow{2}{*}{$T(\mathrm{sec})$} & \multicolumn{2}{c}{$\mathrm{NaCl}$ solution } & \multicolumn{2}{c}{$\mathrm{FeCl}_{3}$} & \multicolumn{2}{c}{ EXCO solution } \\
& As-cast & RRA & As-cast & RRA & As-cast & RRA \\
\hline 0 & 0 & 0 & 0 & 0 & 0 & 0 \\
1200 & 0.0119 & 0.0242 & 0.0119 & 0.0111 & 0.0176 & 0.0113 \\
2400 & 0.0226 & 0.0468 & 0.023 & 0.021 & 0.0333 & 0.0214 \\
3600 & 0.0326 & 0.069 & 0.0326 & 0.0302 & 0.049 & 0.0308 \\
4800 & 0.0419 & 0.0904 & 0.0427 & 0.0386 & 0.0628 & 0.0402 \\
6000 & 0.0513 & 0.1109 & 0.0523 & 0.047 & 0.0785 & 0.0493 \\
7200 & 0.0604 & 0.1331 & 0.0616 & 0.0554 & 0.0924 & 0.0567 \\
\hline
\end{tabular}

predominates, either soluble or indissoluble precipitates. The electrochemical corrosion evaluation provided a complimentary result when compared to the gravimetric method. However, the latter often takes months before any visible corrosion attack could be detected while the former takes just few minutes. This can be a crucial factor for determining the best approach to adopt in corrosion assessment where time is a constraint.

\section{Appendices}

\section{A. Gravimetric and Electrochemical Corrosion Rates Data for Test Specimens in Various Environments}

A.1. Gravimetric Corrosion Rates Data for Test Specimens in Various Media (Exposure Time: 42 Days). For more details, please see Tables 2, 3, 4, 5, 6, 7, and 8 .

\section{A.2. Electrochemical Corrosion Rates Data for Test Specimens} in Various Media (Exposure Time: 2 Hours). For more details, please see Tables $9,10,11,12,13,14$, and 15 .

\section{References}

[1] K. Hashimoto, "2002 W.R. Whitney award lecture: in pursuit of new corrosion-resistant alloys," Corrosion, vol. 58, no. 9, pp. 715-722, 2002.

[2] Z. Sziklarska-Smialowska, Pitting Corrosion of Metals, National Association of Corrosion Engineers, Houston, Tex, USA, 1986.
[3] H. G. Godard, The Corrosion of Light Metals, John Wiley \& Sons, New York, NY, USA, 1967.

[4] L. Garrigues, N. Pebere, and F. Dabosi, "An investigation of the corrosion inhibition of pure aluminum in neutral and acidic chloride solutions," Electrochimica Acta, vol. 41, no. 7-8, pp. 1209-1215, 1996.

[5] R. P. Wei, C. M. Liao, and M. Gao, "A transmission electron microscopy study of constituent-particle-induced corrosion in 7075-T6 and 2024-T3 aluminum alloys," Metallurgical and Materials Transactions A, vol. 29, no. 4, pp. 1153-1160, 1998.

[6] K. A. Yasakau, M. L. Zheludkevich, S. V. Lamaka, and M. G. S. Ferreira, "Role of intermetallic phases in localized corrosion of AA5083," Electrochimica Acta, vol. 52, no. 27, pp. 7651-7659, 2007.

[7] J. H. W. De Wit, "Local potential measurements with the SKPFM on aluminium alloys," Electrochimica Acta, vol. 49, no. 17-18, pp. 2841-2850, 2004.

[8] F. Andreatta, H. Terryn, and J. H. W. de Wit, "Effect of solution heat treatment on galvanic coupling between intermetallics and matrix in AA7075-T6," Corrosion Science, vol. 45, no. 8, pp. 1733-1746, 2003.

[9] N. Birbilis and R. G. Buchheit, "Electrochemical characteristics of intermetallic phases in aluminum alloys : an experimental survey and discussion," Journal of the Electrochemical Society, vol. 152, no. 4, pp. B140-B151, 2005.

[10] J. Wloka, G. Bürklin, and S. Virtanen, "Influence of second phase particles on initial electrochemical properties of AA7010-T76," Electrochimica Acta, vol. 53, no. 4, pp. 20552059, 2007.

[11] A. Pardo, M. C. Merino, S. Merino, M. D. López, F. Viejo, and M. Carboneras, "Influence of SiCp content and matrix composition on corrosion resistance in cast aluminium matrix composites in salt fog," Corrosion Engineering Science and Technology, vol. 39, no. 1, pp. 82-88, 2004.

[12] S. Ren, X. He, X. Qu, I. S. Humail, and Y. Li, "Effect of Si addition to Al-8Mg alloy on the microstructure and thermophysical properties of SiCp/Al composites prepared by pressureless infiltration," Materials Science and Engineering B, vol. 138, no. 3, pp. 263-270, 2007.

[13] A. Pardo, M. C. Merino, R. Arrabal, S. Merino, F. Viejo, and A. E. Coy, "Effect of la surface treatments on corrosion resistance of A3xx.x/SiC p composites in salt fog," Applied Surface Science, vol. 252, no. 8, pp. 2794-2805, 2006.

[14] P. P. Trzaskoma and E. McCafferty, "Corrosion behavior of $\mathrm{SiC} / \mathrm{Al}$ metal matrix composites," Journal of the Electrochemical Society, vol. 130, no. 9, pp. 1804-1809, 1983.

[15] J. Datta, C. Bhattacharya, and S. Bandyopadhyay, "Influence of Cl-, Br-, $\mathrm{NO}_{3}$ and $\mathrm{SO}_{2}$ Ions on the Corrosion Behaviour of 6061 Aluminium Alloy," Indian Academy of Sciences, Bulletin of Materials Science, vol. 28, no. 3, pp. 253-258, 2005. 

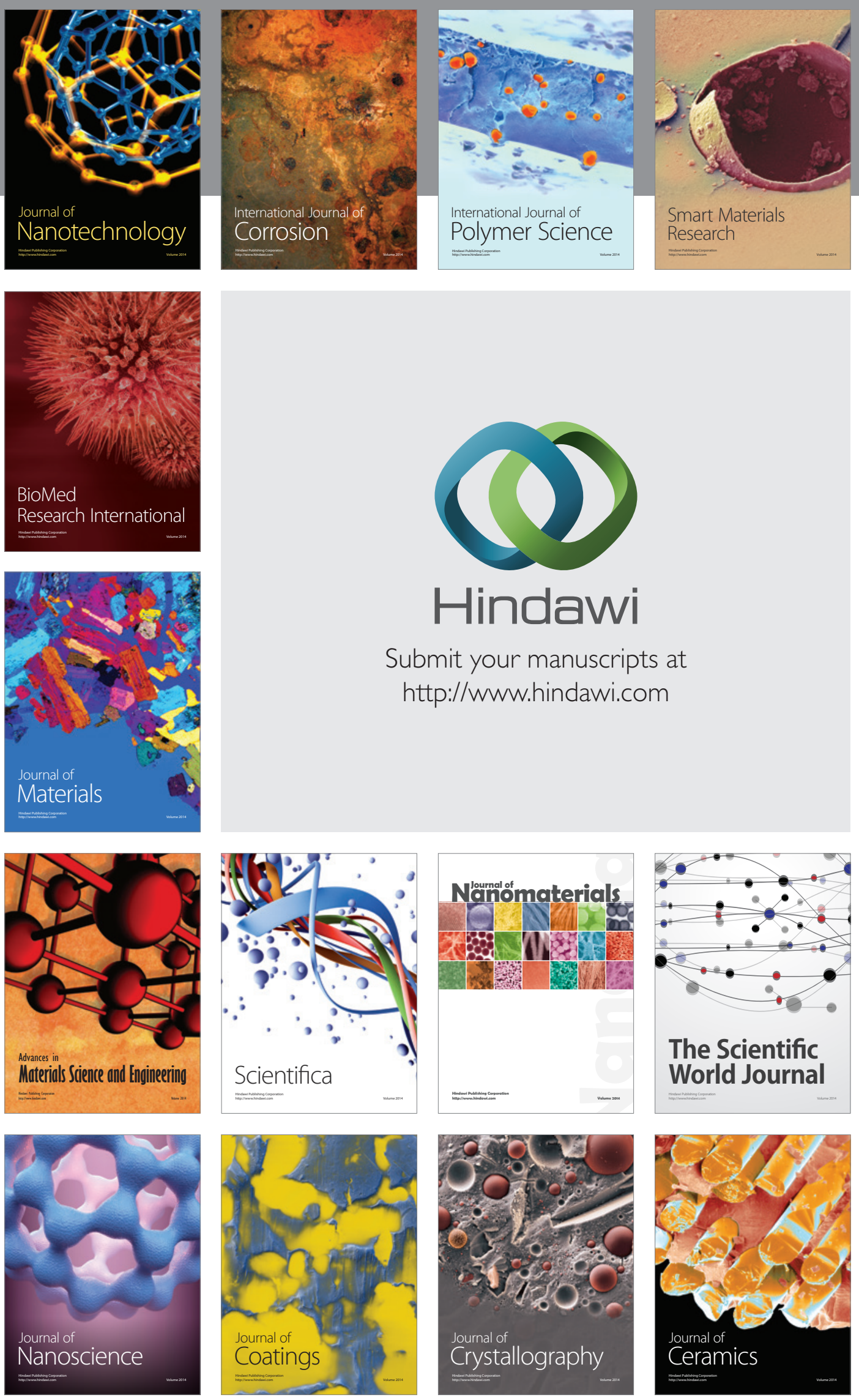

The Scientific World Journal

Submit your manuscripts at

http://www.hindawi.com

\section{World Journal}

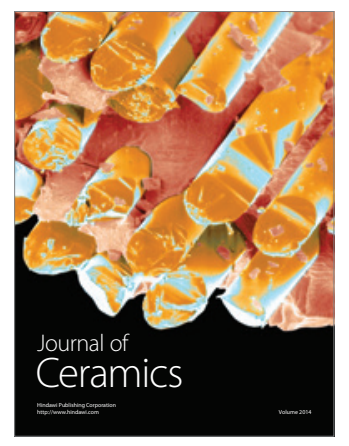

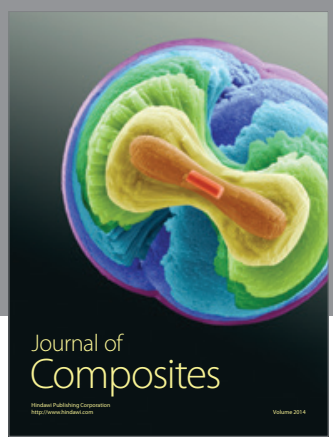
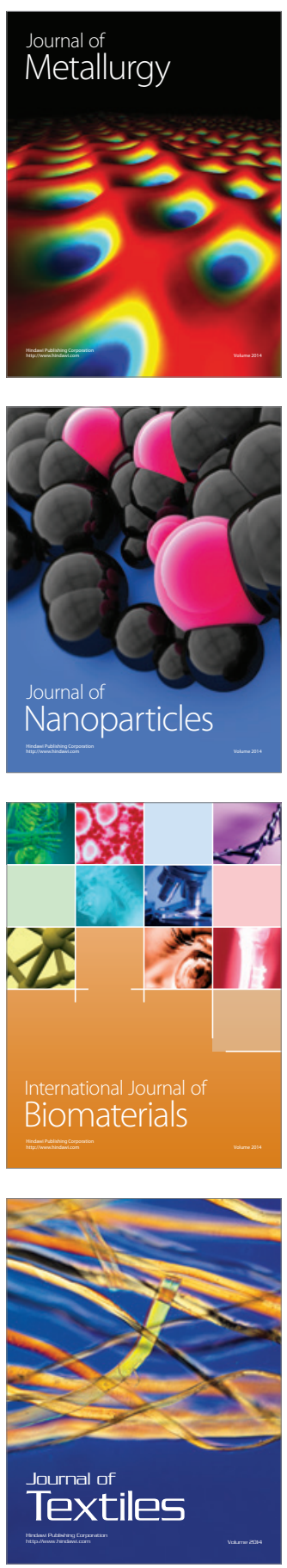